\title{
Descontaminação fotoquímica de alvéolos dentários em técnicas distintas de Terapia Fotodinâmica: relato de dois casos clínicos
}

\author{
Camila Santa Rosa Nunes ${ }^{1}$, Aldo Aparecido Proietti Junior ${ }^{2}$ e \\ Ana Rita Pinheiro Barcessat ${ }^{3}$
}

\begin{abstract}
1 Mestre em Ciências da Saúde pela Universidade Federal do Amapá, Especialista em Gestão em Saúde pela Universidade Federa do Amapá, Especialista em Endodontia pelo Centro Universitário Leonardo da Vinci e graduada em Odontologia pela Universidade Federal do Pará. Dentista da Universidade Federal do Amapá, Brasil.

E-mail: camilasrnunes@gmail.com 1 http://lattes.cnpq.br/3318750226442906 id https://orcid.org/0000-0003-3222-014X
\end{abstract}

2 Doutorando pela Rede de Biodiversidade e Biotecnologia da Amazônia Legal, Mestre em Ciências Biológicas pela Universidade de São Paulo, Especialista em Microbiologia e imunologia pela Universidade Federal do Amapá e graduado em Farmácia e Bioquímica pela Universidade São Francisco. Professor Adjunto do curso de Farmácia da Universidade Federal do Amapá. Pesquisador do Governo do Estado do Amapá atuando no Laboratório Central de Saúde Pública, Brasil.

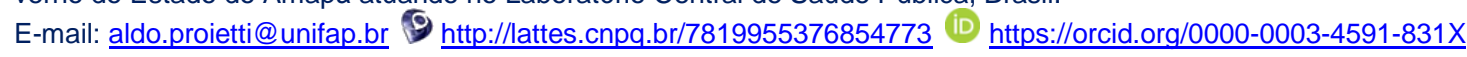

3 Doutora em Estomatologia Básica e Aplicada- Patologia Bucal- pela Universidade de São Paulo, Mestre em Lasers em Odontologia pela Universidade de São Paulo e graduada em Odontologia pela Universidade Federal do Pará. Professora Adjunta do curso de Enfermagem e com atividades no Programa de Pós-Graduação em Ciências da Saúde da Universidade Federal do Amapá, Brasil. E-mail: ritabarcessat@gmail.com $\underline{\text { http://lattes.cnpq.br/1168921254428122 (D) https://orcid.org/0000-0002-5261-6435 }}$

RESUMO: A exodontia é um procedimento cirúrgico que pode apresentar como complicação a infecção da ferida cirúrgica, tal acontecimento pode trazer como consequência um retardo no processo de cicatrização, bem como causar dor pós-operatória ao paciente. Atualmente não existe um protocolo definido a ser realizado após a exodontia que possibilite a redução da carga microbiana de alvéolos contaminados. Logo, é de suma importância pesquisar técnicas que possibilitem diminuir a contaminação no sítio cirúrgico a fim de reduzir a ocorrência de complicações. Neste relato de casos clínicos os autores descrevem a aplicação de duas técnicas de terapia fotodinâmica, a primeira associando a curcumina luz LED azul, e a segunda associando o azul de metileno ao Laser vermelho, para verificar o potencial de redução microbiana de ambas as técnicas nos alvéolos dentários imediatamente após as exodontias. Notou-se que ambas as reduziram efetivamente o percentual microbiano nos alvéolos, a primeira apresentando um percentual de redução de $54 \%$, e a segunda uma redução de $51,86 \%$. Tal redução microbiana pode ter contribuído para uma acelerada cicatrização desse alvéolo bem como ter possibilitado um pós-operatório mais confortável ao paciente.

Palavras-chave: Terapia fotodinâmica. Azul de metileno. Curcumina. Exodontia.

\section{Photochemical decontamination of dental alveols in diferent \\ photodynamic therapy techniques: report of two clinical cases}

ABSTRACT: Exodontia is a surgical procedure that can present as a complication the infection of the surgical wound, such event may result in wound healing delay, as well as can cause patient postoperative. Currently there is no definite protocol to be performed after tooth extractions, which allows the reduction of the microbial load of contaminated alveoli. Therefore, it is extremely important to investigate techniques that can control contamination at the surgical site in order to reduce the occurrence of complications. In this case report the authors describe the application of two photodynamic therapy techniques, the first associating curcumin with blue LED light, and the second associating methylene blue with the Red Laser, in order to verify the microbial reduction potential of both techniques, in dental alveoli immediately after the exodontia. It was observed that both of them effectively reduced the microbial percentage 
in the alveoli, the first presenting a reduction percentage of $54 \%$, and the second a reduction of $51.86 \%$. Such microbial reduction may have contributed to an accelerated healing of this alveolus as well as to have made a more comfortable postoperative period for the patient.

Keywords: Photodynamic therapy. Methylene blue. Curcumin. Exodontia.

\section{INTRODUÇÃO}

O processo de cicatrização decorre de uma resposta organizada e complexa do organismo que visa reestabelecer a saúde do tecido recuperando sua integridade. A utilização de tecnologias que visem acelerar o processo de reparo bem como diminuir a ocorrência de complicações provenientes das suas diversas fases, muitas vezes associado à infecção por patógenos, são sempre muito bem aceitas pela comunidade científica (SILVA et al., 2004).

É nesse contexto que a Terapia Fotodinâmica (TFD) surge como uma importante ferramenta, pois se trata de uma tecnologia de fácil aplicação e que não ocasiona resistência bacteriana. A base da terapia fotodinâmica consiste da interação de três fatores: presença de uma fonte de luz no comprimento de onda adequado, fotossensibilizador não tóxico e presença de oxigênio. Tal interação resultará na produção de espécies reativas de oxigênio como hidroxila e superóxidos, substâncias estas que são capazes de agir em múltiplos alvos da célula bacteriana ou de células neoplásicas, induzindo dessa forma sua morte por apoptose, necrose ou autofagia (CHILAKAMARTHI; GIRIBABU, 2017; PRAZMO et al., 2016.

O potencial indutor de espécies reativas de oxigênio pelo efeito fotodinâmico abre um universo de opções terapêuticas, entretanto há poucas evidências direcionadas para a utilização na clínica após extrações dentárias, que por motivos diversos, ainda se configuram em um dos principais proce- dimentos realizados na odontologia (PASCHOAL et al., 2013; VASCONCELOS, 2014). O presente estudo propõem-se a verificar in vivo a eficácia clínica e antimicrobiana de duas técnicas de terapia fotodinâmica em alvéolos de dentes recém extraídos, uma utilizando a associação curcumina - LED azul outra com azul de metileno e laser vermelho).

\section{RELATO DE CASOS}

O presente trabalho tem aprovação no Comitê de Ética em Pesquisa da Universidade Federal do Amapá, sob o parecer de número 2.073.502, bem como está inscrito na plataforma do Registro Brasileiro de Ensaios Clínicos- REBEC, assegurando-se o sigilo dos dados com assinatura de um Termo de Consentimento Livre e Esclarecido.

\section{Paciente 1:}

Paciente S.S.P.D, 56 anos de idade, leucoderma, gênero feminino, profissional liberal, foi atendida no Consultório Odontológico da Policlínica da Universidade Federal do Amapá, para realização de exodontia do elemento $11 . \mathrm{Na}$ anamnese a paciente não relatou apresentar nenhuma doença sistêmica, bem como não relatou o uso de antibióticos nos últimos 3 meses. Ao exame clínico intra oral e extra oral observou-se presença de doença periodontal e o dente em questão se apresentou com mobilidade grau 3 e presença de exsudato inflamatório. A paciente utilizava-se de prótese parcial removível com má higienização. 


\section{Paciente 2:}

Paciente S.F.A. 34 anos de idade, leucoderma, gênero feminino, diarista, foi atendida no Consultório Odontológico da Policlínica da Universidade Federal do Amapá, para realização de exodontia de raiz residual do elemento 26. Na anamnese a paciente não relatou apresentar nenhuma doença sistêmica, bem como relatou estar sentindo dor localizada e espontânea na região em questão. Ao exame clínico intra e extra oral observou-se presença gengivite. A exodontia do elemento foi indicada pois não era possível a reabilitação do dente devido o avançado estágio da doença cárie.

\subsection{Intervenção Terapêutica}

Na paciente 1 foi realizada a Terapia Fotodinâmica que associou a Curcumina ao LED azul. Foi realizada a anestesia infiltrativa, seguida de descolamento auxiliado por um descolador de Molt, luxação realizada com alavancas seguida da remoção do dente com fórceps. Para verificar o potencial de redução microbiológica da TFD foi realizada uma análise microbiológica antes e após a aplicação da terapia, no qual, após a remoção do dente do interior do alvéolo, foram realizados os seguintes passos (FIGURA 01):

1 Inserção do cone de papel por 10 segundos - $1 \underline{\text { ạ }}$ coleta microbiológica.

2 Gotejamento do fotossensibilizador de curcumina (PDT-Pharma) no interior do alvéolo por 5 minutos.

3 Irradiação da luz LED azul ( $\lambda=470 \mathrm{~nm}$; densidade de energia $=45 \mathrm{~J} / \mathrm{cm}^{2}$; tempo de irradiação= 180 segundos; aparelho Twin Flex MM Optics LTDA-São Carlos - SP - Brasil).

4 Realização da 2a coleta microbiológica.
Figura 01: A) 1a coleta de amostra alveolar B) Gotejamento da curcumina C) Irradiação do LED D) Realização da 2a coleta.

Figure 01: A) first alveoli sample collection B) Curcumin drip C) LED irradiation D) second collection.
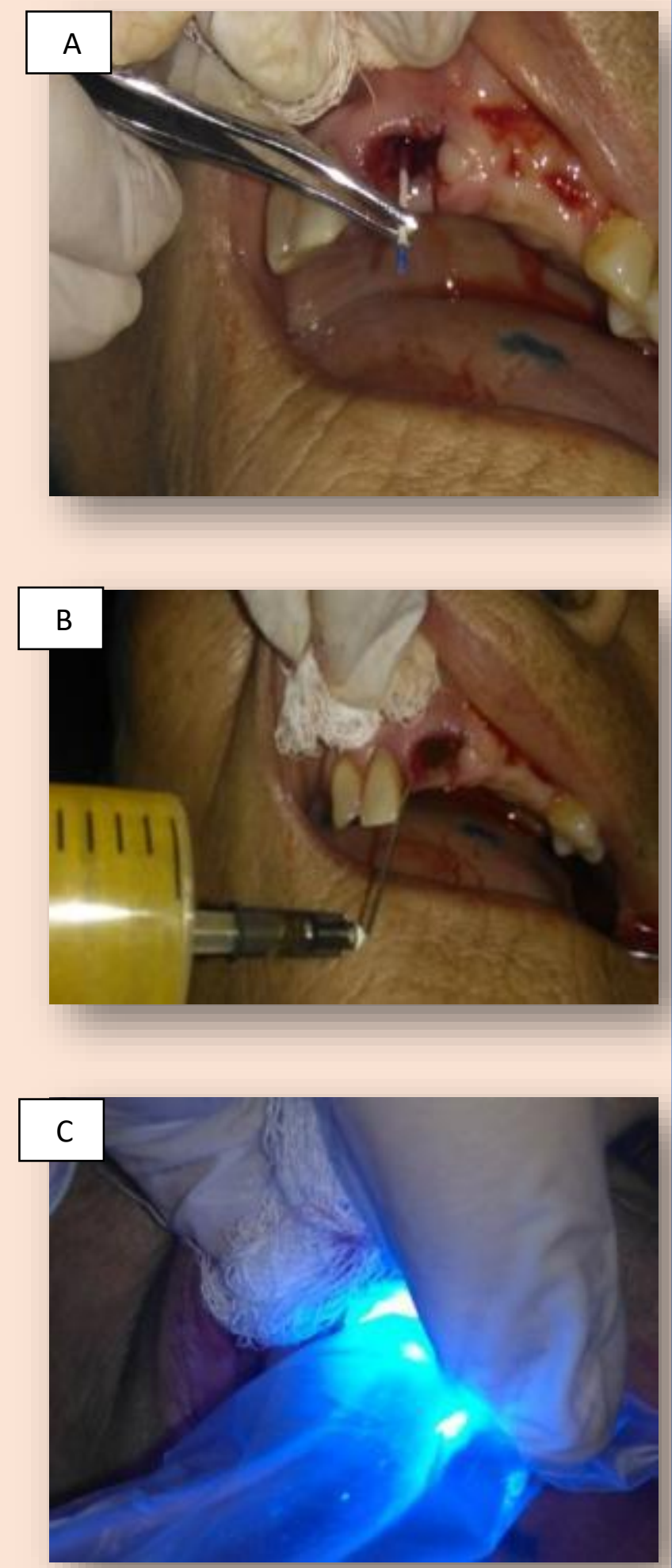


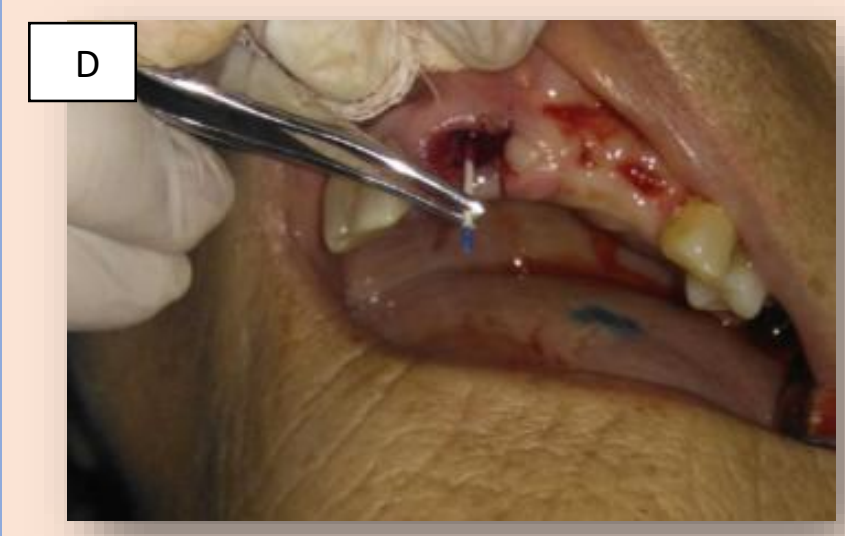

Para a análise microbiológica foram realizados os seguintes procedimentos:

1 Inserção do cone no interior de tubos cônicos plásticos preenchidos com solução salina

2 Transporte ao laboratório de microbiologia num período máximo de 2 horas.

3 Amostras contendo o antes e depois da aplicação da TFD foram agitadas em agitador tipo Vortex para facilitar a dispersão dos microrganismos

4 Diluição da amostra com a finalidade de possibilitar a quantificação das Unidades formadoras de colônias (UFC) num limite não superior a 300 UFC.

5 Semeio de $50 \mu \mathrm{L}$ da solução diluída em meio ágar sangue

6 Incubação em estufa bacteriológica por $24 \mathrm{~h}$, a $37 \circ \mathrm{C}$.

7 Contagem das UFC com auxílio de lupa em contador sob luz emergente.

Na paciente 2 foi realizada a Terapia fotodinâmica que associou o azul de metileno a luz Laser vermelha. Os procedimentos cirúrgicos de remoção do dente desta paciente se assemelham as etapas do primeiro caso. Após a remoção do dente do interior do alvéolo e realização da primeira coleta microbiológica foi realizada a TFD que consistiu nas seguintes ações (FIGURA 04):

1 Gotejamento do fotossensibilizador de azul de metileno (Chimiolux 5) no interior do alvéolo por 5 minutos.

2 Irradiação da luz Laser vermelha $\left(\lambda=660 \mathrm{~nm}\right.$; densidade de energia $=90 \mathrm{~J} / \mathrm{cm}^{2}$; tempo de irradiação= 90 segundos; apareIho Twin Flex MM Optics LTDA-São Carlos SP - Brasil).

Figura 2 - A) Coleta de amostra alveolar B) Gotejamento do azul de metileno C) Alvéolo preenchido com o corante D) Irradiação do LED.

Figure 2 - A) Alveoli sample collection B) Methylene blue dye C) Alveolus filled with the dye d) LED irradiation.
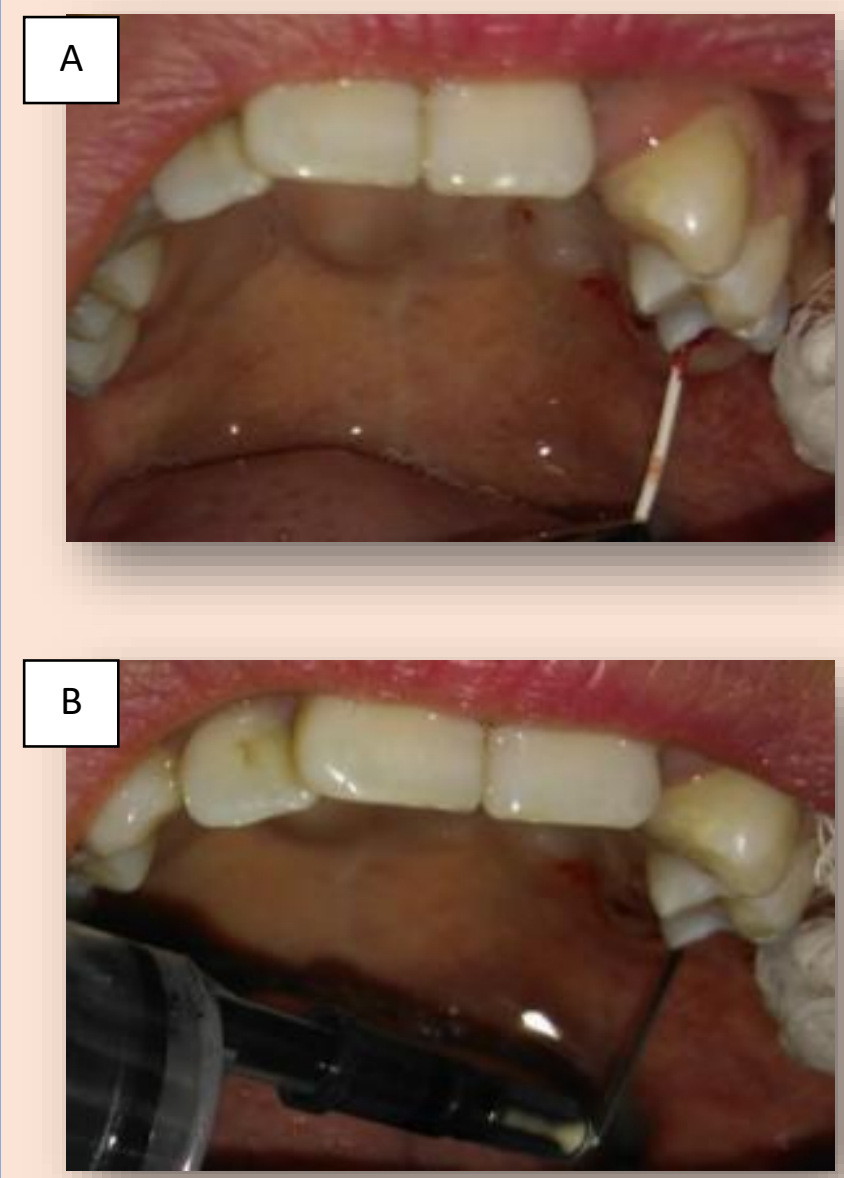

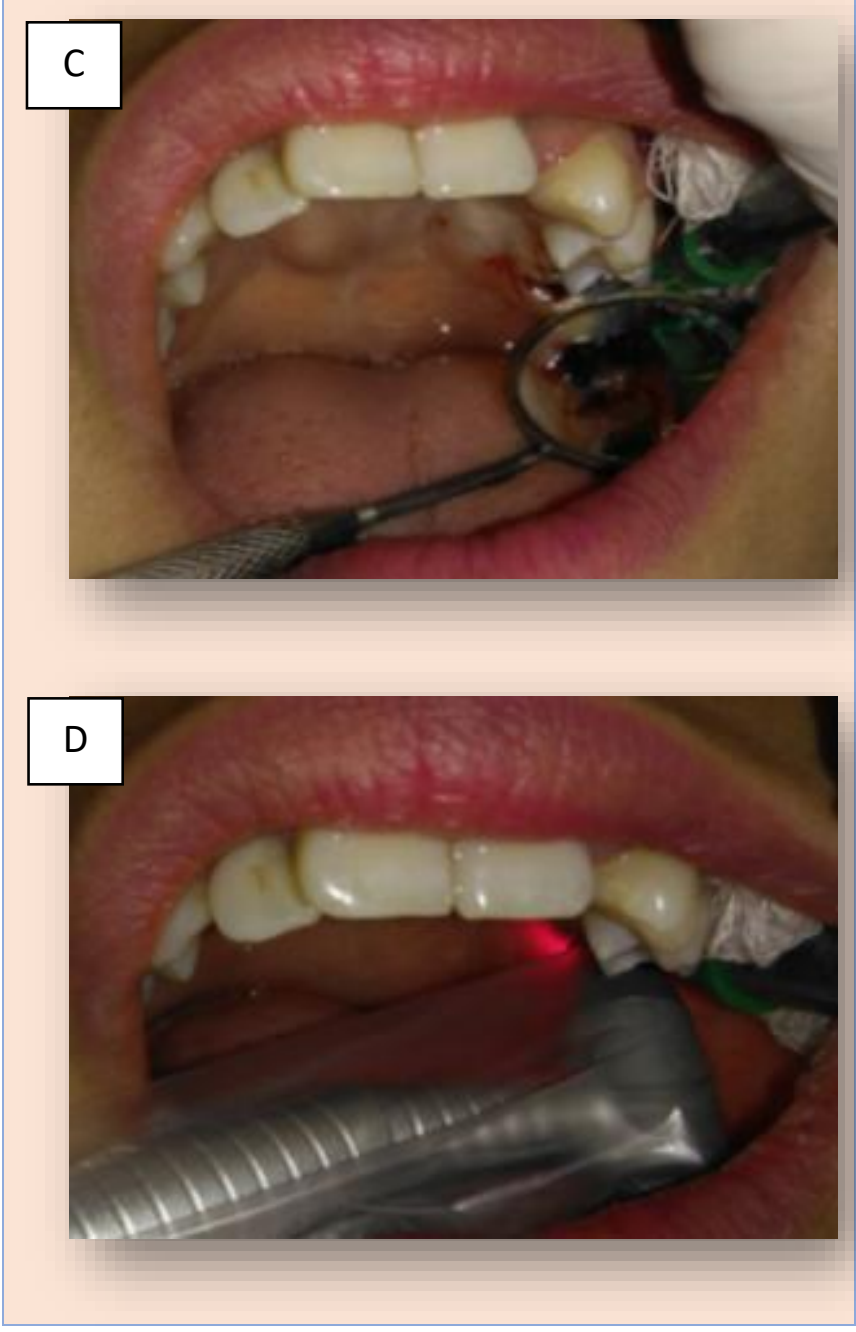

Após remoção do dente do interior do alvéolo foi realizada a 2 a coleta microbiológica. Cessada esta etapa foi realizado os procedimentos laboratoriais semelhantes aos descritos para a paciente 1 para quantificação das UFC.

\section{SEGUIMENTO E RESULTADOS}

Durante o transoperatório nenhuma paciente relatou incomodo como dor ou aquecimento da região proveniente da aplicação da TFD. Quanto ao pós-operatório nenhuma das pacientes relatou dor, sangramento ou edema na região.

Na Figura 03 observam-se as placas com as UFC antes e após a aplicação da terapia para a paciente 1 , na qual foi realizada a TFD com curcumina e luz LED azul. Nota-se que houve uma redução de 155 UFC para 71 UFC, mostrando uma redução de 54,19\%. Enquanto que na Figura 03 observamos na figura $3 \mathrm{~A}$ o alvéolo imediatamente após a cirurgia e na Figura 3B o alveólo cicatrizado 07 dias após o procedimento cirúrgico.

Figura 03 - Unidades formadoras de colônias cultivadas em ágar-sangue da técnica cur+led antes a após aplicação da TFD no alvéolo. Paciente 1 .

Figure 03 - Colony forming units cultured in blood agar from the CUR + LED technique before and after PDT application. Patient 1.

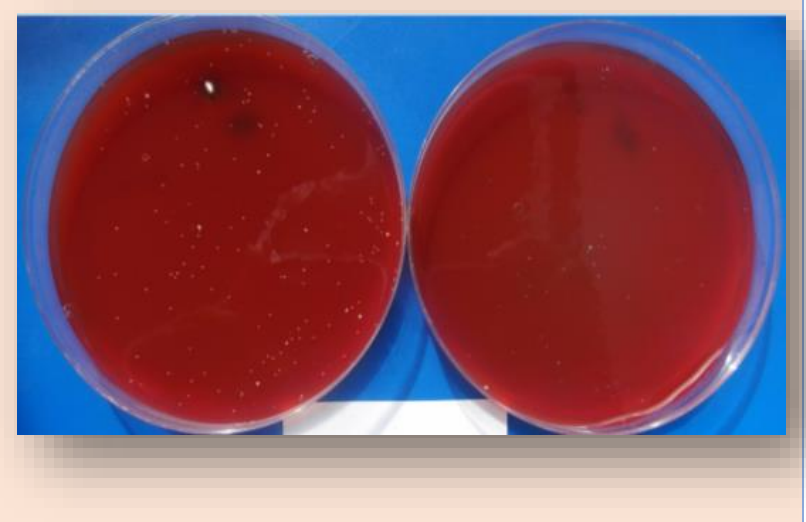


Figura 04 - A) Alvéolo imediatamente após a exodontia e descontaminação por TFD com curcumina e LED; B) Alvéolo após 07 dias do procedimento cirúrgico

Figure 04 - A) Alveolus immediately after the exodontia and TFD curcumine and LED decontamination ; B) Alveolus after 07 days of the surgical procedure.

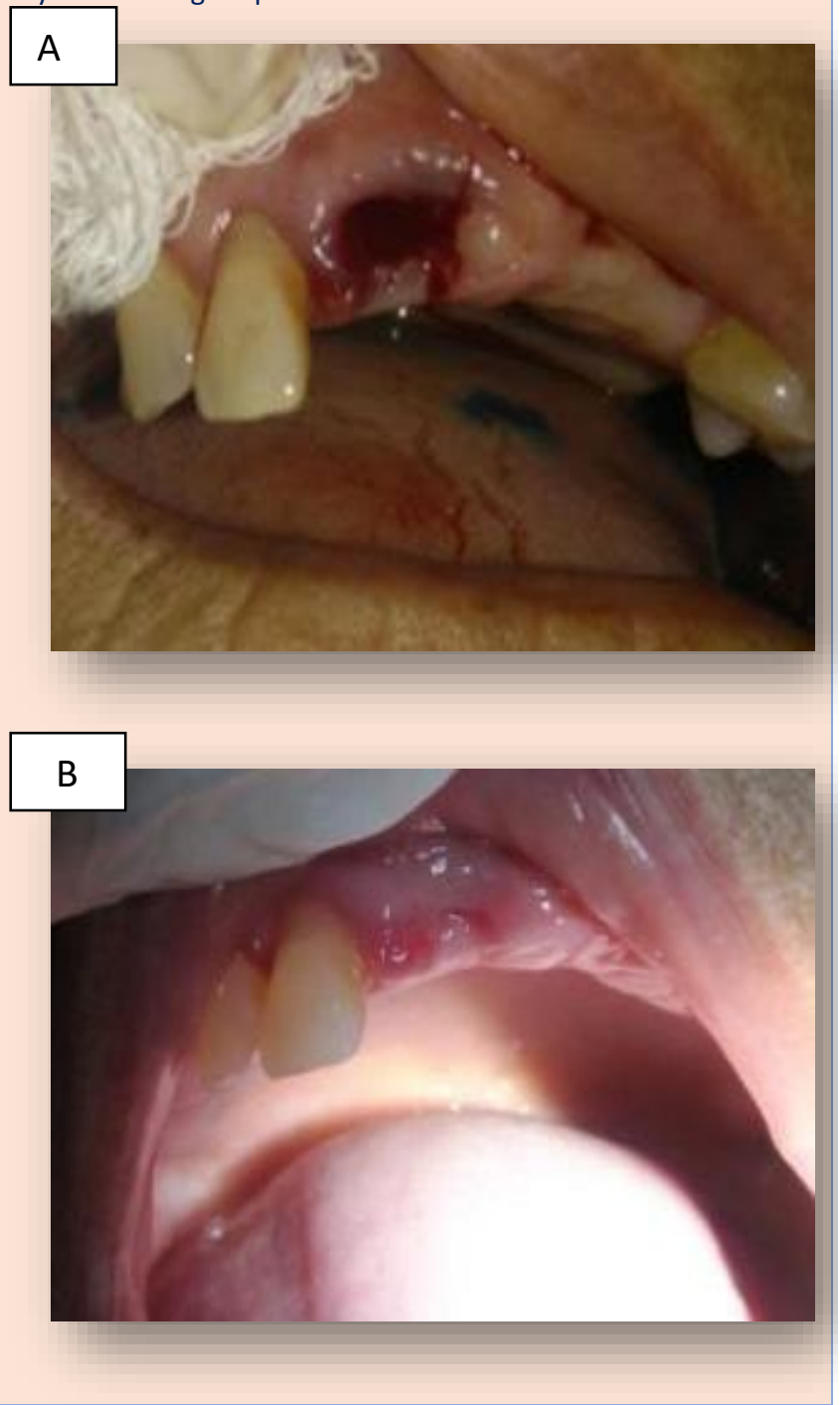

Na Figura 05 podemos visualizar a redução no número de UFC ocasionada pela técnica que associou o azul de metileno ao Laser vermelho, onde nota-se uma redução de 51,86\%, passando de 241 UFC para 116 UFC. Na Figura 06, podemos visualizar o alvéolo logo após a cirurgia e no seu 70 dia de cicatrização.
Figura 05 - Unidades formadoras de colônias cultivadas em Ágar-sangue do grupo AM+Laser antes a após aplicação da TFD. Figure 5 - Colony forming units cultured in blood Agar of the $\mathrm{MB}+$ laser group before and after PDT application.

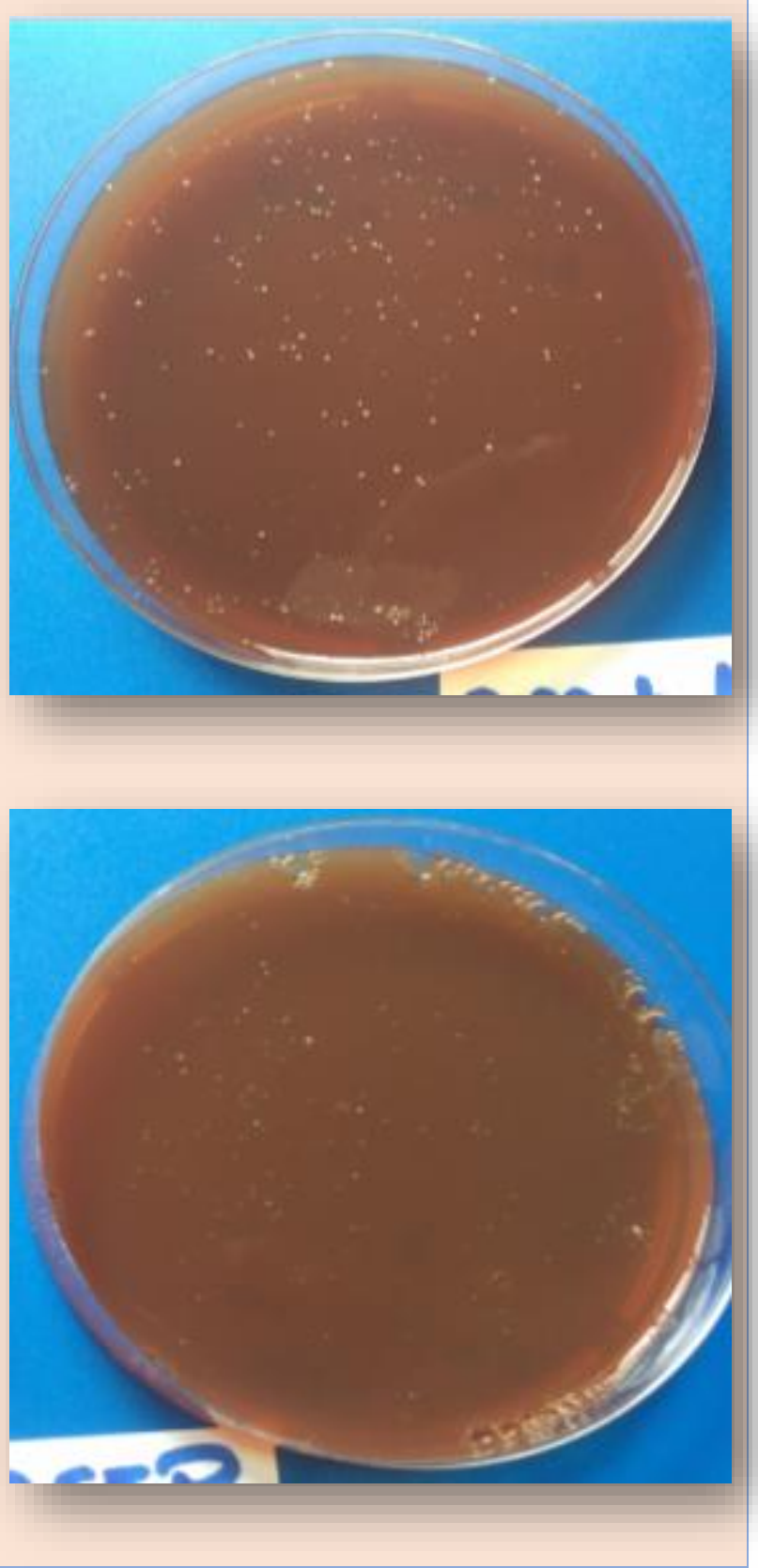


Figura 06 - A) Alvéolo imediatamente após a exodontia e descontaminação por TFD com AM e laser; B) Alvéolo após 07 dias do procedimento cirúrgico.

Figure 06 - A) Alveolus immediately after the exodontia and decontamination by $\mathrm{MB}$ and laser ; B) Alveolus after 07 days of the surgical procedure.

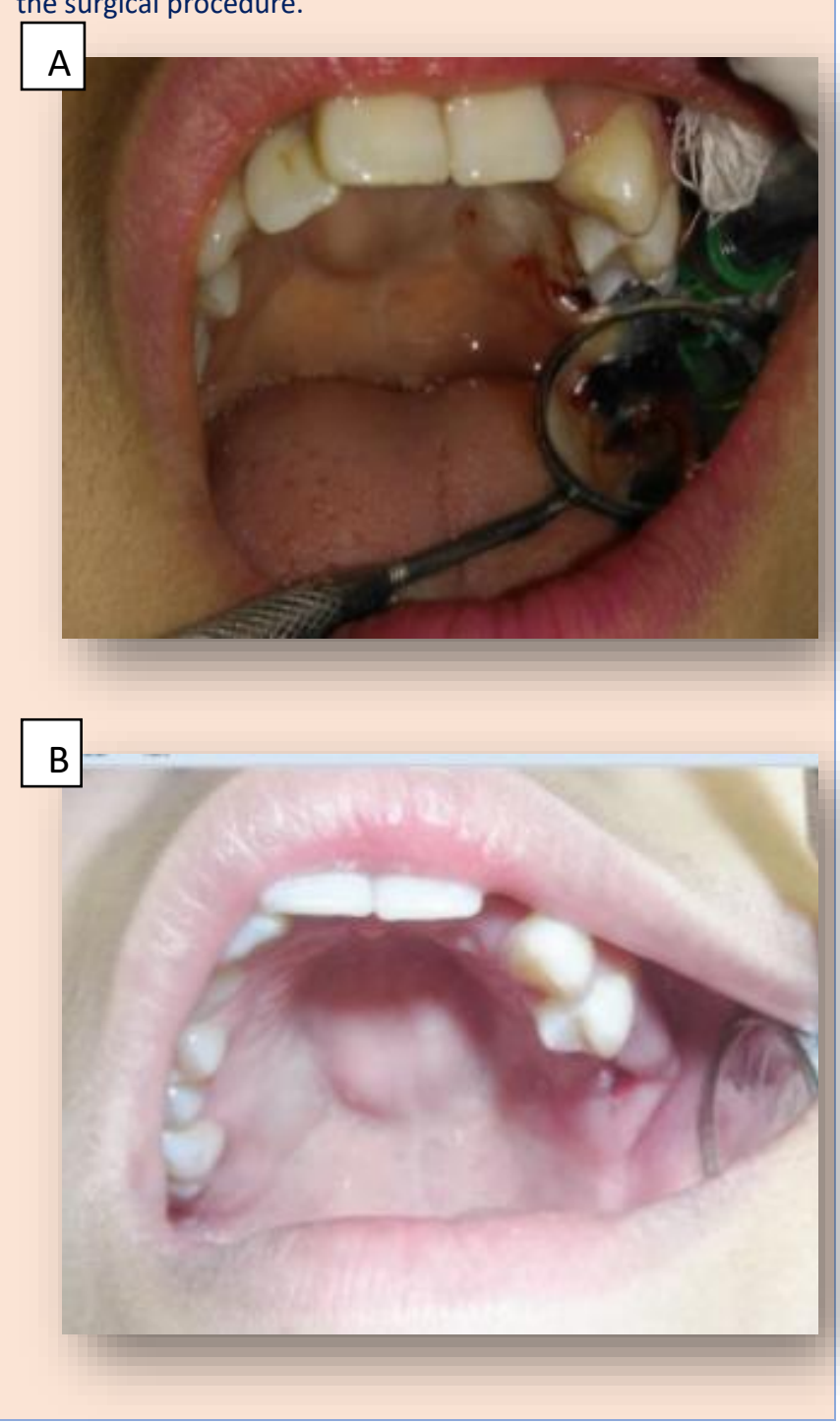

\section{DISCUSSÃO}

O percentual de redução no número de bactérias para ambas as técnicas se mostraram inferiores a pesquisas já publicadas. Pesquisas que utilizaram a associação de curcumina com luz LED azul encontraram reduções de 68\% (ARAÚJO et al., 2012a), 71\% (PASCHOAL et al.,2013) e 99\% (ARAÚJO et al., 2012b). Para a técnica que associou o azul de metileno ao laser vermelho encon- tramos percentuais de redução de $63 \%$ (FONTANA et al; 2009), 73\% (ARAÚJO et al., 2009), 99\% (CHAN; LAI, 2003).

No presente estudo os percentuais de redução alcançaram um pouco mais que $50 \%$, porém deve se ressaltar que pesquisas realizadas in vitro, com utilização de cepas padrão tendem a apresentar resultados de redução superior a testes in vivo, pois quanto maior a quantidade de espécies, maior é a possibilidade de intercâmbio entre os microrganismos (PANHÓCA et al., 2016, TONON et al, 2015; FONTANA et al, 2009). Esta potencial desvantagem pode ser contornada com a utilização de uma segunda aplicação da técnica, ou com a alteração dos parâmetros utilizados, como, por exemplo, a densidade de energia, concentração de fotossensibilizador e tempo de pré-irradiação.

A TFD após exodontias pode servir como mecanismo de redução de contaminação do sítio da cirurgia, minimizando a necessidade de antimicrobianos sistêmicos, pois poderá promover maior eficiência na descontaminação local desses alvéolos (VASCONCELOS, 2014). É importante ressaltar que não existe um protocolo definido em cirurgia oral para ser realizado no alvéolo após exodontia, sendo o uso de solução fisiológica e curetagem o mais realizado clinicamente. Porém, tal solução não possui efeito bactericida, o que favorece a utilização da TFD como terapia adicional com a vantagem de ser uma tecnologia de baixo custo e fácil aplicação, que possui uma ação local não promovendo efeitos citotóxicos ou térmicos na loja cirúrgica, e nem ocasionando resistência bacteriana (THEODORO et al., 2015).

A escolha do fotossensibilizador e da fonte de irradiação é sempre um ponto importante a considerar. $O$ presente estudo sugere que as técnicas se equivalem tanto na 
redução bacteriana quanto no conforto pós-operatório do paciente, o que pressupõe liberdade de escolha clínica pelo fotossensibilizador e fonte de luz mais acessíveis. $\mathrm{O}$ azul de metileno é financeiramente mais viável que a curcumina comercial, no entanto, no presente estudo foi utilizado um equipamento laser $660 \mathrm{~nm}$ de custo mais elevado que o LED azul necessário para ativar a curcumina e cujo equipamento tem uso corriqueiro nos consultórios odontológicos para fotopolimerização de resinas, dentre outras finalidades (ALVES, 2011).

A terapia fotodinâmica, nas condições deste relato de caso, se mostrou uma opção válida para ser utilizada como terapia adicional de descontaminação de alvéolos infectados, porém estudos maiores devem ser realizados para comprovar tal efeito, bem como avaliar se essa redução microbiana refletirá num processo de cicatrização e reparo mais acelerado e confortável ao paciente.

\section{REFERÊNCIAS}

ALVES, O. A. Avaliação da eficiência do diodo emissor de luz (LED) emitindo em 460 $\mathrm{nm}$ associado à curcumina na fotossensibilização letal de Candida albicans e de Aggregatibacter actinomycetemcomitans. 2011. 93 f. Dissertação (Mestrado) - Curso de Engenharia Mecânica, Departamento de Engenharia Mecânica, Universidade Federal de Minas Gerais, Belo Horizonte, 2011.

ARAÚJO, N. C. et al. Photodynamic effects of curcumin against cariogenic pathogens. Photomedicine and laser surgery, v. 30, n. 7, p. 393-399, 2012a. https://doi.org/10. 1089/pho.2011.3195

ARAÚJO, N. C. et al. Overall-mouth disinfection by photodynamic therapy using curcu- min. Photomedicine and laser surgery, v. 30, n. 2, p. 96-101, 2012b. https://doi.org/ 10.1089/pho.2011.3053 ARAúJO, P.. V. et al. In vitro lethal photosensitization of $S$. mutans using methylene blue and toluidine blue $\mathrm{O}$ as photosensitizers. Acta odontologica latinoamericana, v. 22, n. 2, p. 93-97, 2009.

CHAN, Y.; LAl, C.-H. Bactericidal effects of different laser wavelengths on periodontopathic germs in photodynamic therapy. Lasers in medical science, v. 18, n. 1, p. 51-55, 2003.

CHILAKAMARTHI, U.; GIRIBABU, L. Photodynamic Therapy: Past, Present and Future. The Chemical Record, 2017. https://doi. org/10.1002/tcr.201600121

FONTANA, C. R. et al. The antibacterial effect of photodynamic therapy in dental plaque-derived biofilms. Journal of periodontal research, v. 44, n. 6, p. 751-759, 2009. https://doi.org/10.1111/j.1600-0765.2008. 01187.x

PANHÓCA, V. H. et al. Oral Decontamination of Orthodontic Patients Using Photodynamic Therapy Mediated by Blue-Light Irradiation and Curcumin Associated with Sodium Dodecyl Sulfate. Photomedicine and laser surgery, v. 34 , n. 9, p. 411-417, 2016.

https://doi.org/10.1089/pho.2015.4080

PASCHOAL, M. A. et al. Photodynamic potential of curcumin and blue LED against Streptococcus mutans in a planktonic culture. Photodiagnosis and photodynamic therapy, v. 10, n. 3, p. 313-319, 2013. https:// doi.org/10.1016/i.pdpdt.2013.02.002 PRAŻMO, E. J. et al. Photodynamic Therapy As a Promising Method Used in the Treatment of Oral Diseases. Advances in clinical and experimental medicine: official organ Wroclaw Medical University, v. 25, n. 4, p. 
799-807, 2016.

SILVA, J. C. E. et al. Evaluation of the use of low level laser and photosensitizer drugs in healing. Lasers in surgery and medicine, $v$. 34, n. 5, p. 451-457, 2004. https://doi.org/ $10.1002 / \mathrm{Ism} .20062$

THEODORO, L. H. et al. Effect of antimicrobial photodynamic therapy on periodontally infected tooth sockets in rats. Lasers in medical science, v. 30, n. 2, p. 677-683, 2015. https://doi.org/10.1007/s10103-013-1400-

\section{8}

TONON, C. C. et al. Comparative effects of photodynamic therapy mediated by curcumin on standard and clinical isolate of Streptococcus mutans. The journal of contemporary dental practice, v. 16, n. 1, p. 16, 2015. https://doi.org/10.5005/ip-journals -10024-1626

VASCONCELOS, X. T. P. de. Efeitos da Terapia Fotodinâmica Antimicrobiana na descontaminação de alvéolos com lesão periapical imediatamente pós-exodontia. 2014. 64 f. Dissertação (Mestrado) - Curso de Clínica Odontológica, Universidade Federal do Ceará, Fortaleza, 2014.

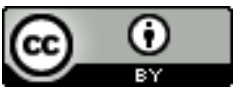

License information: This is an openaccess article distributed under the terms of the Creative Commons Attribution License, which permits unrestricted use, distribution, and reproduction in any medium, provided the original work is properly cited.

Artigo recebido em 08 de março de 2018.

Avaliado em 04 de julho de 2018.

Aceito em 23 de julho de 2018.

Publicado em 28 de fevereiro de 2019.

\section{Como citar este artigo (ABNT):}

NUNES, Camila Santa Rosa; PROIETTI JUNIOR, Aldo Aparecido; BARCESSAT, Ana Rita Pinheiro. Descontaminação fotoquímica de alvéolos dentários em técnicas distintas de Terapia Fotodinâmica: relato de dois casos clínicos. Estação Científica (UNIFAP), Macapá, v. 8, n. 2, p. 3-4, maio/ago. 2018. 